\title{
Remote sensing of atmospheric water vapor variation from GPS measurements during a severe weather event
}

\author{
Dong-Seob Song and Dorota A. Grejner-Brzezinska \\ Satellite Positioning and Inertial Navigation (SPIN) Laboratory, The Ohio State University, Columbus, OH 43210, USA
}

(Received November 21, 2008; Revised April 23, 2009; Accepted July 8, 2009; Online published November 30, 2009)

\begin{abstract}
The Global Positioning System (GPS) provides a relatively inexpensive method to remotely sense atmospheric water vapor in all weather conditions. In this study, we applied the GPS meteorology technique to monitor the precipitable water vapor (PWV) variation during a severe weather event (typhoon EWINIAR). The Korean weighted mean temperature equation (KWMTE), customized for the Korean Peninsula, was used to improve the accuracy of the GPS PWV estimation. The time series and the comparison with the images of MTSAT/CMAX and the GPS PWV contour maps indicated that the temporal change of GPS PWV was closely related to the progress of the typhoon. The correlation between the maximum GPS PWV and the maximum rainfall caused by the typhoon was also higher than that for the quiet weather period. Furthermore, the peak in the time series of GPS PWV was generally in good agreement with the time when the maximum rainfall was recorded. Our results therefore confirm that GPS meteorology is an efficient PWV sensing technique, capable of capturing the complex characteristics of water vapor distribution and its temporal variation during a period of severe weather events.

Key words: GPS meteorology, typhoon EWINIAR, precipitable water vapor, Korean weighted mean temperature equation.
\end{abstract}

\section{Introduction}

A typhoon is a meteorological phenomenon that brings heavy rain and strong winds. Recording the variation in atmospheric water vapor during the passage of a typhoon is particularly important as it is the main source of precipitation and a dominant constituent of energy resources related to typhoon dynamics (Frank, 1977). Liou et al. (2001) reported that the Global Positioning System (GPS) meteorology technique offers a high accuracy of GPS precipitable water vapor (PWV) retrieval during severe weather conditions, such as a typhoon, hurricane, and tornado.

The first study carried out by GPS meteorology techniques during severe weather conditions was a GPS/STORM experiment, which took place in the tornado high-risk area of the Midwestern USA (Rocken et al., 1995). Liou and Huang (2000) suggested that the data on the PWV obtained from the GPS observations were generally in good agreement with that observed by the radiosonde during typhoon ZEB. Foster et al. (2003) found that the rainfall predictions obtained from a mesoscale spectral model of the storm consistently underestimated the observed high values. Spatial and temporal water vapor distributions provided by continuous GPS PWV measurements are therefore indispensable to monitoring and predicting the characteristic aspects of typhoons (Liou et al., 2001), and with the increasing number of permanently tracking GPS receivers worldwide, the achievable spatial and temporal resolutions of GPS PWV continue to improve (Yan et al.,

Copyright (c) The Society of Geomagnetism and Earth, Planetary and Space Sciences (SGEPSS); The Seismological Society of Japan; The Volcanological Society of Japan; The Geodetic Society of Japan; The Japanese Society for Planetary Sciences; TERRAPUB.
2008).

In this study, a high-accuracy PWV was estimated using continuous observation data from the Korean permanent GPS network during the passage of typhoon EWINIAR, which occurred on July 10, 2006. The Gipsy-Oasis II (GOA II) software, developed by the Jet Propulsion Laboratory (JPL), was used to process the data, and the GPS PWV results were then compared with those obtained from the radiosonde during the progress of EWINIAR.

It should be noted that the significant damage caused by this typhoon was reported in South Korea, where $150 \mathrm{~km}^{2}$ (60 square miles) of farmland across the nation was subject to flooding due to torrential rainfall. Landslides and flooding destroyed roads and levees, while over 600 houses were damaged in South Cholla province. The Korea Meteorological Administration (KMA) reported that up to $234 \mathrm{~mm}$ of rain had fallen on the southern areas of South Korea, while a total rainfall of 199-260 mm was reported in Hamyang County in South Kyongsang province.

For the procedure of GPS PWV retrieval from the zenith wet delay, we adopted a regionally weighted mean temperature model $\left(T_{\mathrm{m}}\right)$, which was calculated by a linear regression method using surface and upper air temperature. This model is compared with other, previously published models of $T_{\mathrm{m}}$. We analyzed the correlation between the maximum GPS PWV and maximum rainfall to verify that GPS can play a significant role in monitoring temporal variations of water vapor fields during severe weather events. In addition, the time lag between the peak times of maximum GPS PWV and maximum rainfall was compared to demonstrate the correlation of spatio-temporal variations of GPS PWV and the rainfall. These results may have practical ap- 


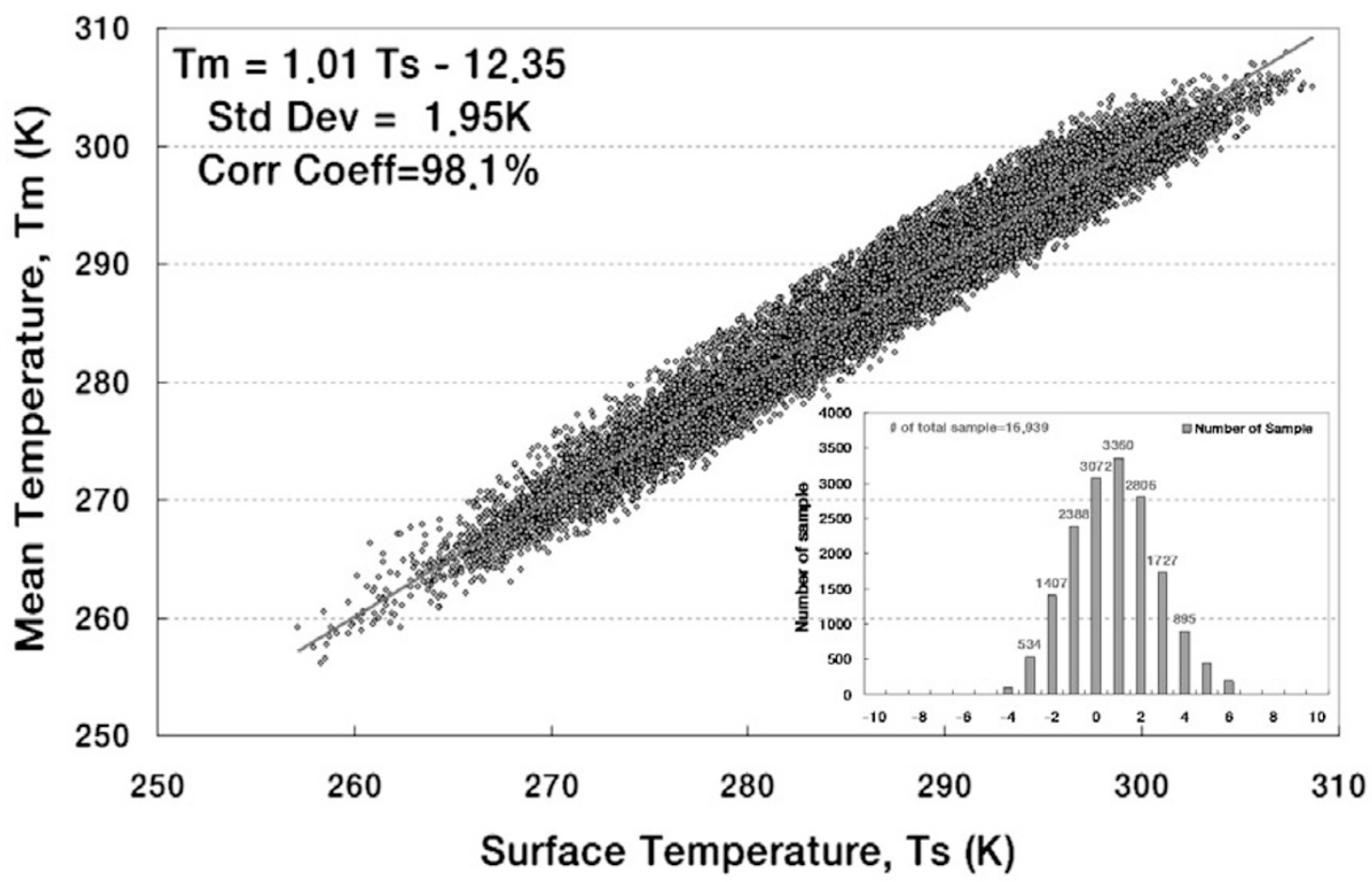

Fig. 1. Linear regression analysis between surface temperature $T_{\mathrm{s}}$ and mean temperature $T_{\mathrm{m}}$; the histogram represents the distribution of the differences between $T_{\mathrm{s}}$ and $T_{\mathrm{m}}$.

plications, such as providing constraining PWV estimates for numerical weather models, which is particularly valuable during severe weather events. It should also be mentioned that GPS PWV can be used, for example, to improve predictions of heavy rainfall during extreme conditions, as demonstrated in Section 4, via the analysis of the correlation between GPS PWV and rainfall.

\section{Estimation of GPS Signal Delay and Retrieval of PWV}

The high-accuracy GPS carrier phase measurements that can be converted to distances from the GPS satellites to the ground-based receiver can be used for Zenith Total Delay (ZTD) estimation (Hong et al., 2008). This task requires a GPS data processing software designed for high-accuracy geodetic measurements. The GOA II software (Lichten and Border, 1987) used in this study estimates the ZTD and other nuisance parameters using a constrained batch least-squares inversion procedure. The ZTD consists of the zenith hydrostatic delay (ZHD) and the zenith wet delay (ZWD). The ZHD is mainly deduced from the content of neutral gases in the atmosphere and can be accurately computed using surface pressure (Elgered et al., 1997). The ZWD is related to the water vapor content in the troposphere and can be derived by extracting the ZTD and then subtracting the ZHD computed using the surface pressure readings (Duan et al., 1996). The ZHD has a magnitude of about $2,300 \mathrm{~mm}$ at sea level. It is possible to predict the ZHD to better than $1 \mathrm{~mm}$, provided the surface pressure readings are accurate to $0.3 \mathrm{hPa}$ (millibar) or better.

In this study, we estimated the ZTD at $1-\mathrm{h}$ intervals for each GPS station during the 24-h sessions, using GPS data from 22 stations for the period of July 7-11, 2006. The GPS PWV solution was calculated from the ZWD obtained from the ZTD by subtracting the ZHD, which was computed using the surface meteorological data in the Saastamoinen hydrostatic model (Bevis et al., 1992).

$$
\mathrm{ZHD}=\frac{(2.2779 \pm 0.0024[\mathrm{~mm} / \mathrm{hPa}]) \cdot P_{\mathrm{s}}}{1-0.00266 \cdot \cos 2 \varphi-0.00028\left[\frac{1}{\mathrm{~km}}\right] \cdot h}
$$

where $P_{\mathrm{s}}$ : total atmospheric pressure at surface/antenna site [hPa]; $\varphi$ : geodetic latitude of the site; $h$ : ellipsoidal height $[\mathrm{km}]$.

The ZWD was converted to the PWV as follows (Bevis et al., 1992):

$$
\mathrm{PWV}=\Pi \times \mathrm{ZWD}
$$

where

$$
\Pi=\frac{10^{8}}{\rho \cdot R_{\mathrm{v}} \cdot\left[\left(k_{3} / T_{\mathrm{m}}\right)+k_{2}^{\prime}\right]}
$$

where $\rho$ is the density of water $\left(\mathrm{kg} / \mathrm{m}^{3}\right), \quad R_{\mathrm{v}}$ is the specific gas constant of water vapor $(\mathrm{J} / \mathrm{kg}-\mathrm{K}), k_{2}^{\prime}$ is $22.1 \pm 2.2(\mathrm{~K} / \mathrm{mb}), k_{3}$ is $(3.739 \pm 0.012) \times 10^{5}\left(\mathrm{~K}^{2} / \mathrm{mb}\right)$, and $T_{\mathrm{m}}$ is the weighted mean temperature of the atmosphere $(\mathrm{K})$. The $T_{\mathrm{m}}$ was originally defined by Davis et al. (1985), and it relates to the water vapor pressure and temperature profile at a site. The accuracy of PWV estimates is proportional to the accuracy of $T_{\mathrm{m}}$ (Ross and Rosenfeld, 1997; Wang et al., 2005). Jade et al. (2005) suggested that the best possible accuracy of the PWV retrieval from the observed ZWD can be achieved if the conversion constant in Eq. (3) is estimated 

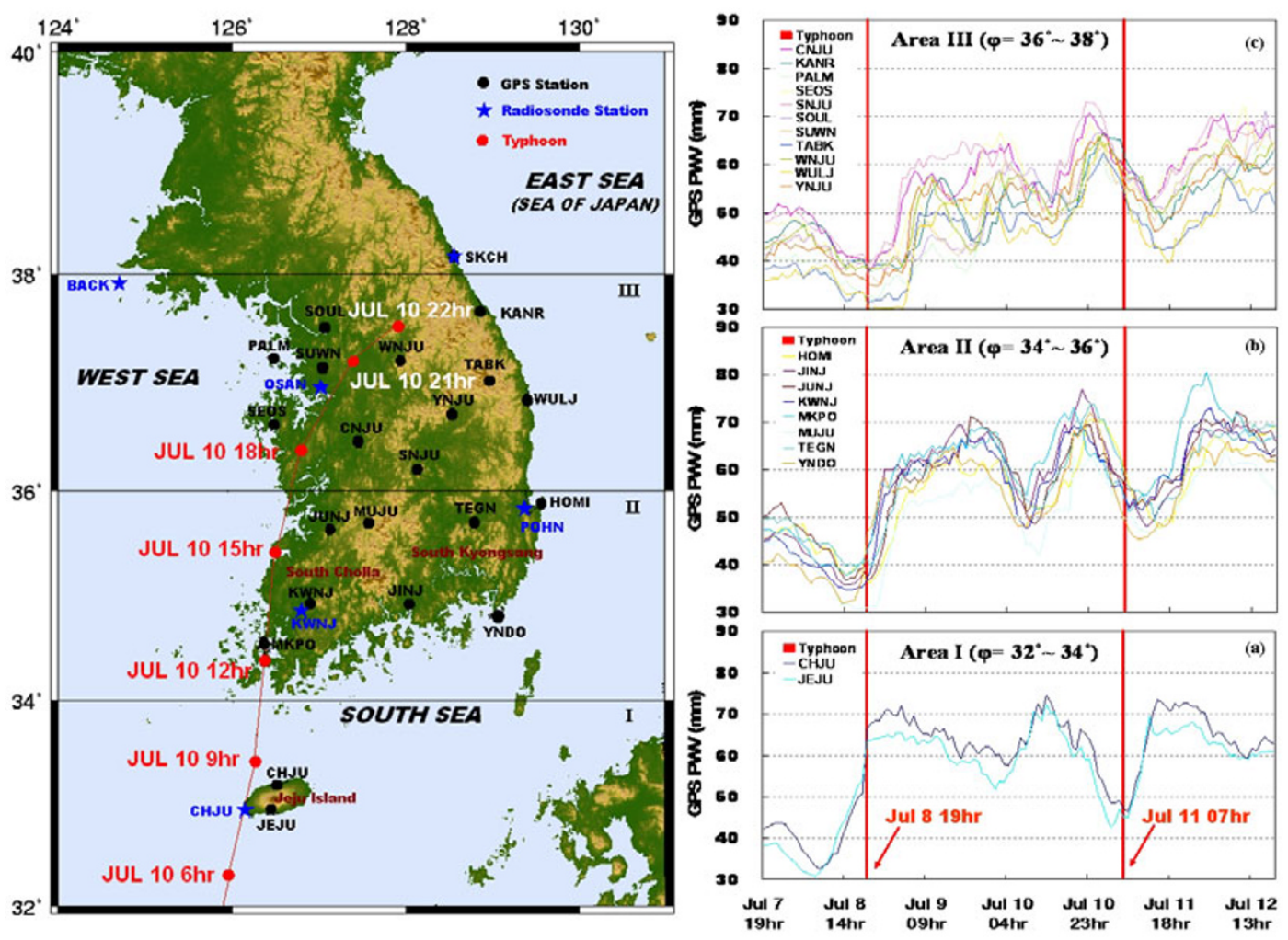

Fig. 2. Left panel: distribution of the GPS stations (black dots) and radiosonde sites (blue star) and the route of typhoon EWINIAR (red line). The area between $\varphi=32^{\circ}$ and $\varphi=34^{\circ}$ is labeled as area I, between $\varphi=34^{\circ}$ and $\varphi=36^{\circ}$ as area II, and between $\varphi=36^{\circ}$ and $\varphi=38^{\circ}$ as area III. Right panel: the time series of GPS PWV in area I (a), area II (b) and area III (c).

using a value of $T_{\mathrm{m}}$ that is tuned to the specific geographic area and season. Consequently, the $T_{\mathrm{m}}$, derived by Bevis et al. (1992) for the USA may not be suitable for South Korea, which has a different climate.

We therefore calculated the Korean Weighted Mean Temperature Equation (KWMTE) using the linear regression method between $T_{\mathrm{s}}$, acquired from the Automated Weather Station (AWS), and $T_{\mathrm{m}}$, acquired from six radiosonde stations, for a period of 2003-2005 (see Fig. 1 and Eq. (4)).

$$
T_{\mathrm{m}}=1.01 \times T_{\mathrm{s}}-12.35
$$

The correlation coefficient of KWMTE reaches $98.1 \%$ and the root mean square error (RMSE) is $1.95 \mathrm{~K}$. The KWMTE is significantly different from the general formulation determined by Bevis et al. (1992), with a corresponding RMSE of $4.74 \mathrm{~K}$, which was derived from radiosonde data at 13 U.S. stations over a 2-year period. Song (2006) evaluated the accuracy of the KWMTE through a comparison with other models (Bevis et al., 1992; Mendes, 1999; Solbrig, 2000; Liou et al., 2001; Schüler, 2001) for the determination of the most accurate weighted mean temperature of the atmosphere for the Korean Peninsula. It was demonstrated that a regionally optimized model can provide improved results, as compared to the global models suggested by Mendes (1999) and Schüler (2001).

\section{Remote Sensing of GPS PWV Variation During the Passage of EWINIAR}

Figure 2 (left panel) displays the geographic locations of the 22 GPS stations and six radiosonde stations that were used to determine the KWMTE and the route of typhoon EWINIAR (right panel), as well as the time series of the hourly GPS PWV estimations at each station during the 5 days analyzed. The GPS PWV is at the level of less than $50 \mathrm{~mm}$ nationwide until 17:00 hours on July 8, before the arrival of typhoon EWINIAR at the Korean Peninsula (see Fig. 2). Notice that the PWV at CHJU and JEJU stations, located on Jeju Island (area I), southern Korea, rise sharply to $>60 \mathrm{~mm}$ at 19:00 hours on July 8 due to the indirect impact of the typhoon, while the upper latitude areas (marked II and III in Fig. 2) did not show any increase at that time.

Two hours later, the PWV of all inland stations increased sharply as the typhoon moved northward. The GPS PWV displays some decrease when the strength of the typhoon changed from 'strong' to 'middle' (06:00 hours July 10). However, at 15:00 hours on July 10, the PWV began to increase again, even though the central pressure of typhoon EWINIAR was $985 \mathrm{hPa}$, while the maximum wind speed of $23 \mathrm{~m} / \mathrm{s}$ around $35.5^{\circ} \mathrm{N}$ and $126.5^{\circ} \mathrm{E}$ had weakened (area II). The reasons for the increased water vapor are: (1) the typhoon's residual energy, and (2) the monsoon, a seasonal rain, moving northward across the Korean Peninsula. After the typhoon dissipated, the GPS PWV observed in area III decreased slower than that in the lower latitudinal areas (I and II). Overall, the GPS PWV shows high magnitudes before and during typhoon EWINIAR's passage over the Korean peninsula, and low values after the event. This result confirms that the temporal change of GPS PWV is closely related with the course of a typhoon. 

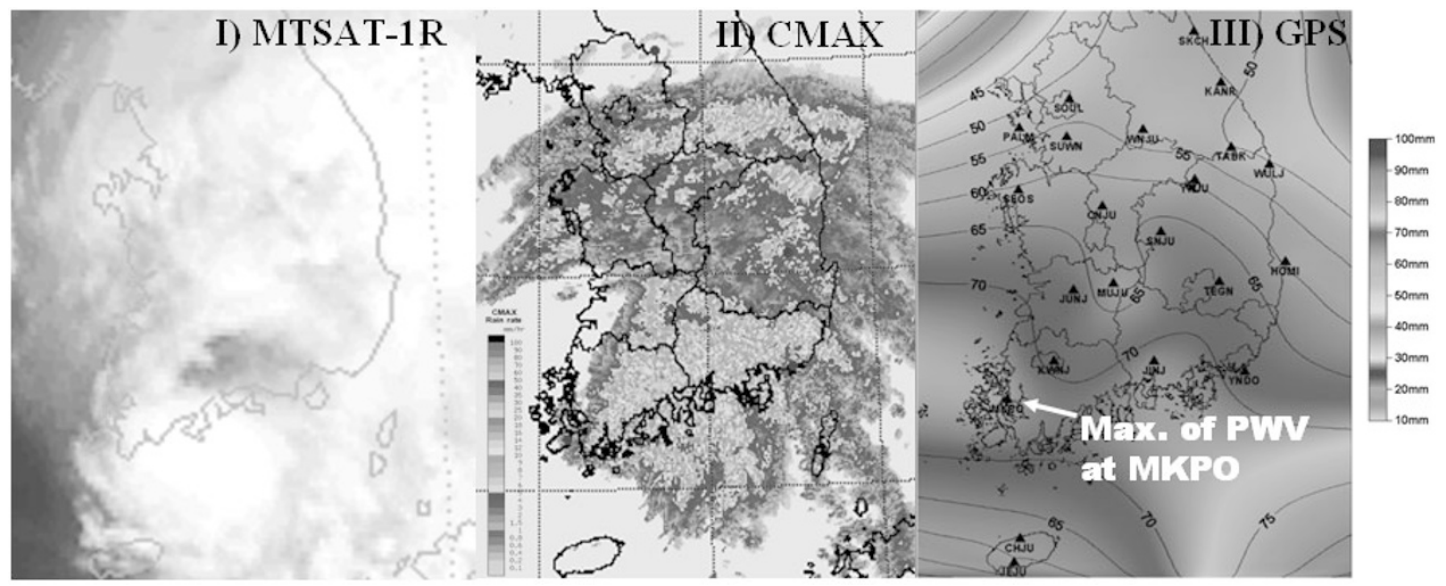

(a) 10:00 July 10, 2006

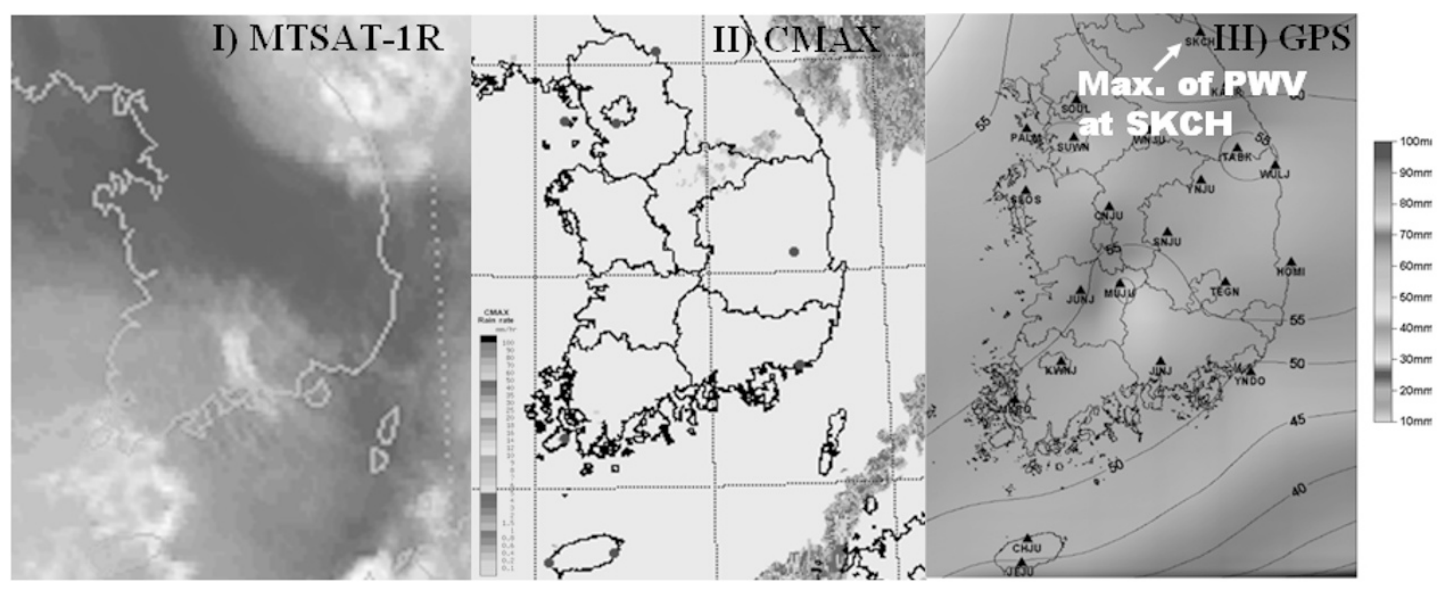

(b) 22:00 July 10, 2006

Fig. 3. MTSAT image (left), CMAX image (middle), and GPS PWV contour map (right).

Figure 3 illustrates the comparison between the GPS PWV obtained from the 22 GPS stations and the image from the MTSAT satellite and the CMAX (Constant Maximum) image from the ground radar. The contour plots of the GPS PWV obtained from the hourly GPS data processing were created by the minimum curvature method using the SURFER software. Figure 3(a) shows the images and a contour map of the GPS PWV observed at 10:00 hours on July 10, the time at which typhoon EWINIAR struck the western shores of South Korea. The figure indicates that the GPS PWV at MKPO is larger than that at other stations. Overall, not only the GPS PWV, but also the water vapor information in the MTSAT-1R and CMAX images shows significant values over the entire Korean Peninsula during the course of the typhoon. However, as shown in Fig. 3(b), the GPS PWV was recorded at a level below $60 \mathrm{~mm}$ over land after the typhoon had passed and dissipated, except for the highest value $(\sim 70 \mathrm{~mm})$ at the $\mathrm{SKCH}$ station, which is located in the northeastern side of the peninsula. This result confirms that a dense GPS network may be efficiently used for sensing water vapor distribution and its temporal changes. The GPS PWV showed sensitivity to geographical location as the typhoon moved northward, which indicates that the accumulation of spatio-temporal PWV data com- bined with the wind fields and air pressure gradients can contribute to improvements in the prediction of a typhoon's track. Since GPS can be used under all weather conditions and is capable of providing real-time, accurate, and inexpensive PWV data with high spatio-temporal resolutionas compared to other instruments for PWV sensing, such as radiosondes, which may provide biased measurements during inclement weather conditions-we expect that PWV derived from the Korean regional GPS network will be used for weather forecasting as initial constraints in the numerical weather models, particularly during severe weather.

\section{Analysis of GPS PWV During a Severe Weather Event}

The objective of this analysis was to validate the GPS PWV retrieval process during a severe weather event in South Korea and to verify the accuracy of PWV derived from GPS relative to that of radiosonde sounding data.

Figure 4 shows the scatter plots of PWV from the collocated radiosonde and GPS stations for five sites using the KWMTE and the Bevis WMTE (BWMTE), respectively. The red line in Fig. 4 represents a linear regression fit to the PWV data. Using Eq. (3), the RMSE of the fit was $5.28 \mathrm{~mm}$ when KWMTE was used and reached $5.99 \mathrm{~mm}$ 


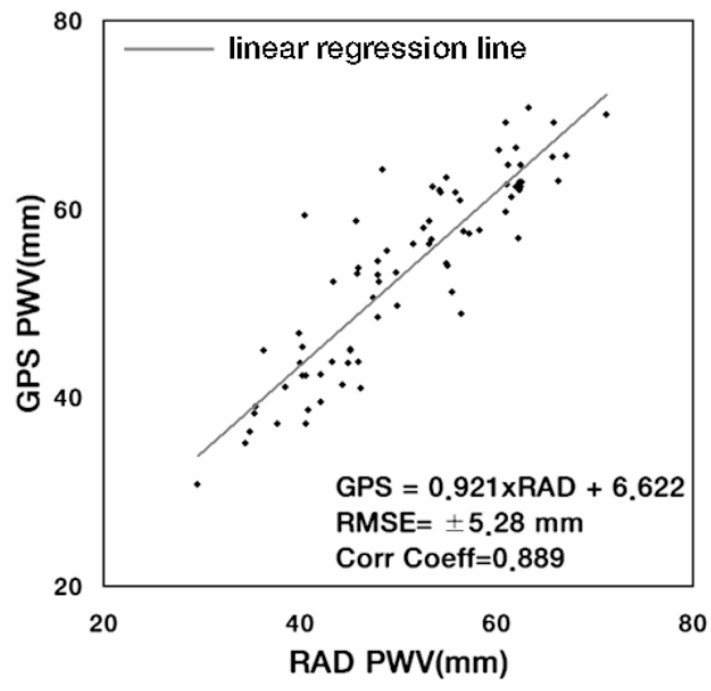

(a) KWMTE

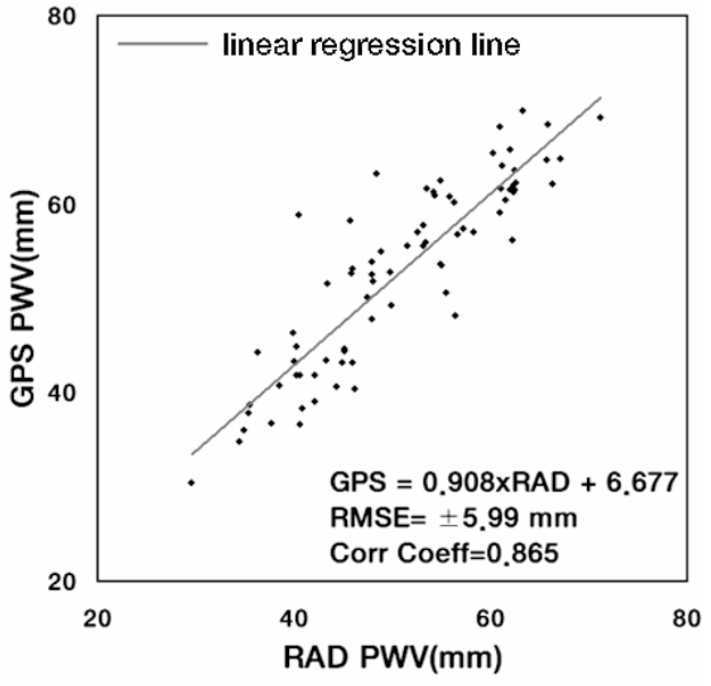

(b) Bevis WMTE

Fig. 4. Scatter plot of PWV from two sensors, GPS and radiosonde, at five tested sites.

Table 1. Statistical results of a comparison between GPS PWV with KWMTE and radiosonde PWV in terms of the mean bias (GPS-radiosonde), standard deviation (SD), root mean square error (RMSE) and separation between GPS and radiosonde at five different locations.

\begin{tabular}{lcccc}
\hline GPS station & Bias $(\mathrm{mm})$ & SD $(\mathrm{mm})$ & RMSE $(\mathrm{mm})$ & Separation $(\mathrm{km})$ \\
\hline HOMI & 8.18 & 5.60 & 9.77 & 20.1 \\
JEJU & 2.71 & 3.24 & 4.11 & 28.9 \\
SKCH & 4.91 & 2.57 & 5.49 & 5.7 \\
KWNJ & 1.21 & 3.63 & 3.75 & 16.0 \\
SUWN & 0.03 & 3.76 & 3.67 & 15.1 \\
\hline
\end{tabular}

when BWMTE was applied. Furthermore, a stronger correlation was found between GPS PWV, converted by the KWMTE, and the radiosonde PWV (correlation coefficient 0.889), as compared to the case when the BWMTE was used (correlation coefficient 0.865 ). The relative difference of GPS PWV induced by both models can be derived from Eq. (3) as follows:

$$
\frac{\Delta \mathrm{PWV}}{\mathrm{PWV}}=10^{-8} \cdot \Pi \cdot \rho \cdot R_{\mathrm{v}} \cdot \frac{k_{3}}{\left(k_{3}+k_{2}^{\prime}\right) T_{\mathrm{m}}} \cdot \frac{\Delta T_{\mathrm{m}}}{T_{\mathrm{m}}} \approx \frac{\Delta T_{\mathrm{m}}}{T_{\mathrm{m}}}
$$

since $10^{-8} \cdot \Pi \cdot \rho \cdot R_{\mathrm{v}} \cdot k_{3} \cdot\left[\left(k_{3}+k_{2}^{\prime}\right) T_{\mathrm{m}}\right]^{-1}$ is a very small value.

In this study, the surface temperature varies from $\sim 289 \mathrm{~K}$ to $\sim 306 \mathrm{~K}$. On the basis of Eq. (5), the relative difference between GPS PWV obtained with KWMTE and BWMTE, respectively, at the surface temperature of $289 \mathrm{~K}$, is $0.45 \%\left(\Delta T_{\mathrm{m}}=1.26 \mathrm{~K}\right)$, and the difference of $2.13 \%$ $\left(\Delta T_{\mathrm{m}}=6.19 \mathrm{~K}\right)$ corresponds to the highest surface temperature of $306 \mathrm{~K}$. The differences in RMSE and the correlation coefficient resulting from the use of both formulas were caused by these relative errors. Therefore, we suggest that the KWMTE model is more suitable and accurate for tracking severe weather events around the Korean peninsula. Also, we expect that the use of a local model, such as a seasonal/monthly weighted mean temperature equation, may reduce a relative bias that may occur in PWV due to varying temperature and humidity conditions during differ- ent seasons.

The values for coefficients $a$ and $b$ were estimated by the least-squares method in KWMTE as $0.921(\mathrm{~m} / \mathrm{m})$ and $6.622(\mathrm{~mm})$, respectively (Fig. 4(a)). After we removed this bias, the RMSE was reduced by $2.85 \mathrm{~mm}$, giving a final value of $2.45 \mathrm{~mm}$. The statistical results for the five tested sites are listed in Table 1. The comparison of PWV from two sensors shows that biases are small and range from 0.03 to $4.91 \mathrm{~mm}$, with the exception of the HOMI station. The minimum RMSE value of $3.7 \mathrm{~mm}$ corresponds to SUWN station, and the maximum of $9.8 \mathrm{~mm}$ is at HOMI. No obvious correlation can be observed between the relative accuracy of GPS PWV, as compared with the radiosonde PWV, with the station separation, such as for HOMI station, as shown in Table 1. Also, the larger RMSE $( \pm 5.74$ $\mathrm{mm})$ and smaller correlation coefficient $\left(r^{2}=0.83\right)$ occur during the passage of the typhoon, as compared to the period unaffected by the typhoon (RMSE $= \pm 4.38 \mathrm{~mm}$ and $\left.r^{2}=0.96\right)$. This indicates that it is possible that the radiosonde PWV may not represent an exact reference for the evaluation of GPS PWV accuracy for a typhoon period with strong winds. In fact, it is necessary to use more reliable and more accurate equipment, such as a water vapor radiometer (WVR), in order to properly evaluate the GPS PWV accuracy. However, given the lack of alternatives to radiosondes in Korea (there is just one WVR there, which was not operational during the passage of typhoon EWINIAR), radiosonde PWV is used here, even if these 


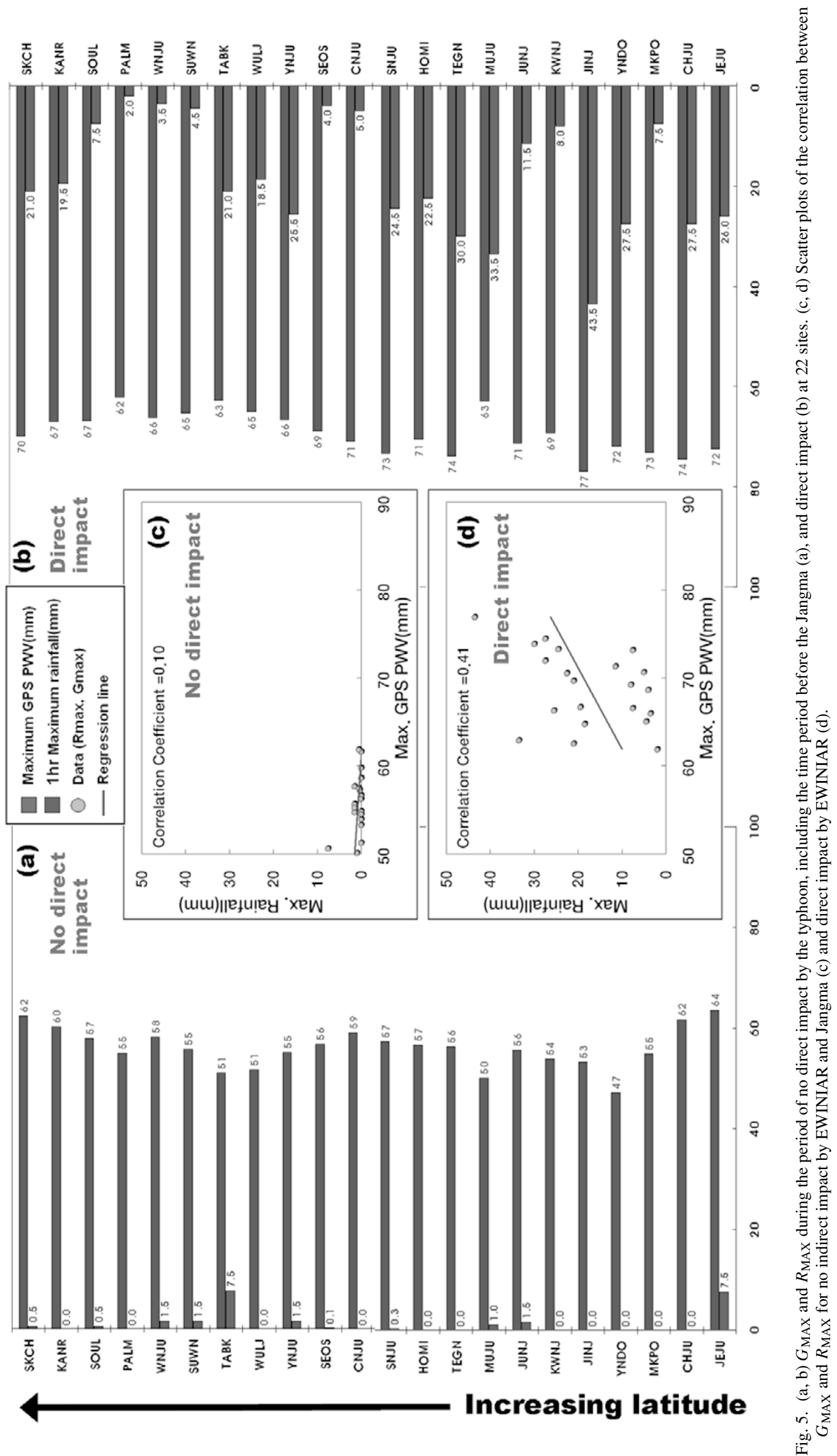




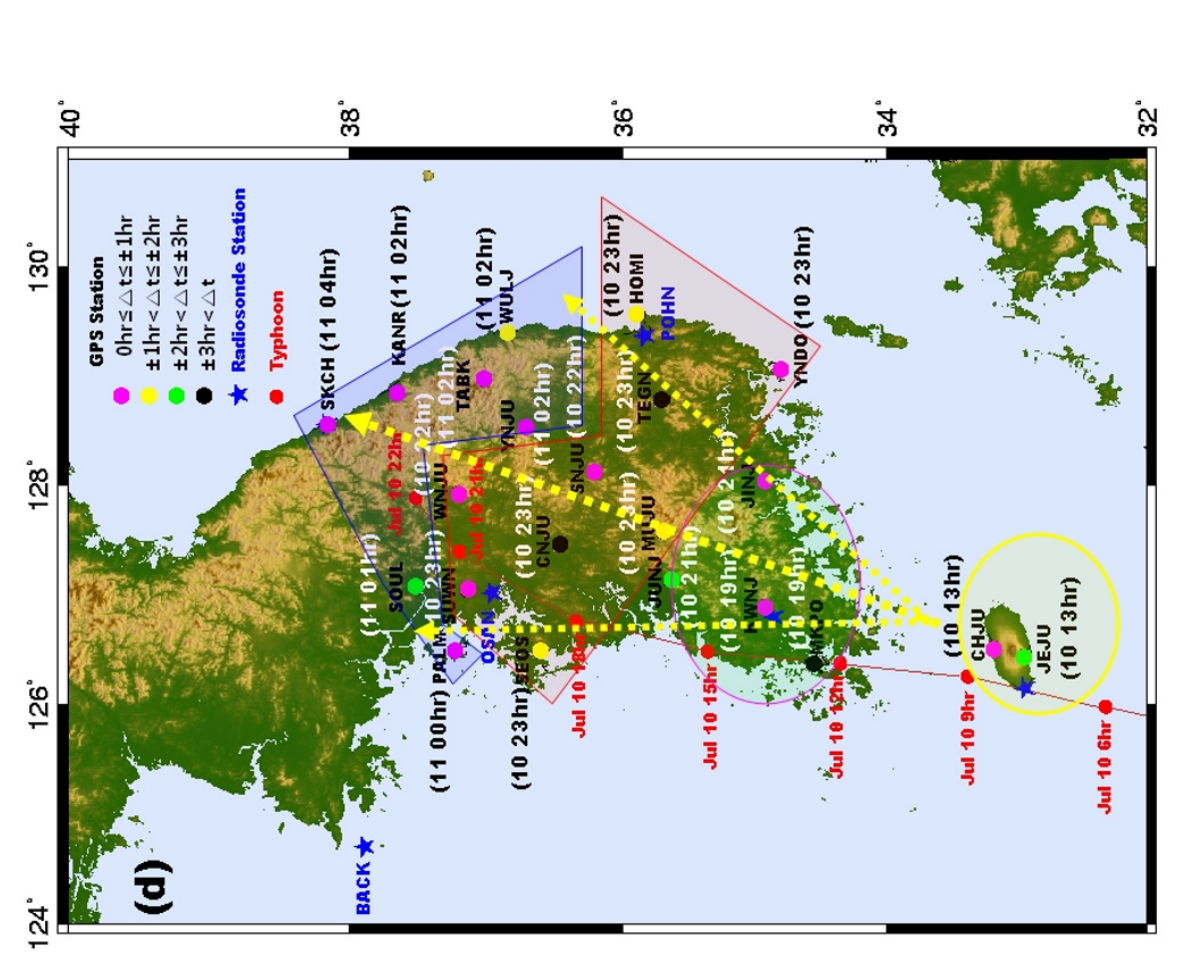

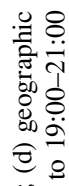

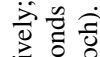

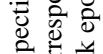

造

异导

完

콣

总完造

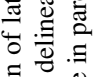

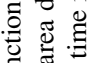

罗哭

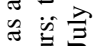

过

ขั้

응

ठิ

Oे क्षे

웡

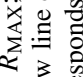

응

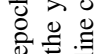

苛完
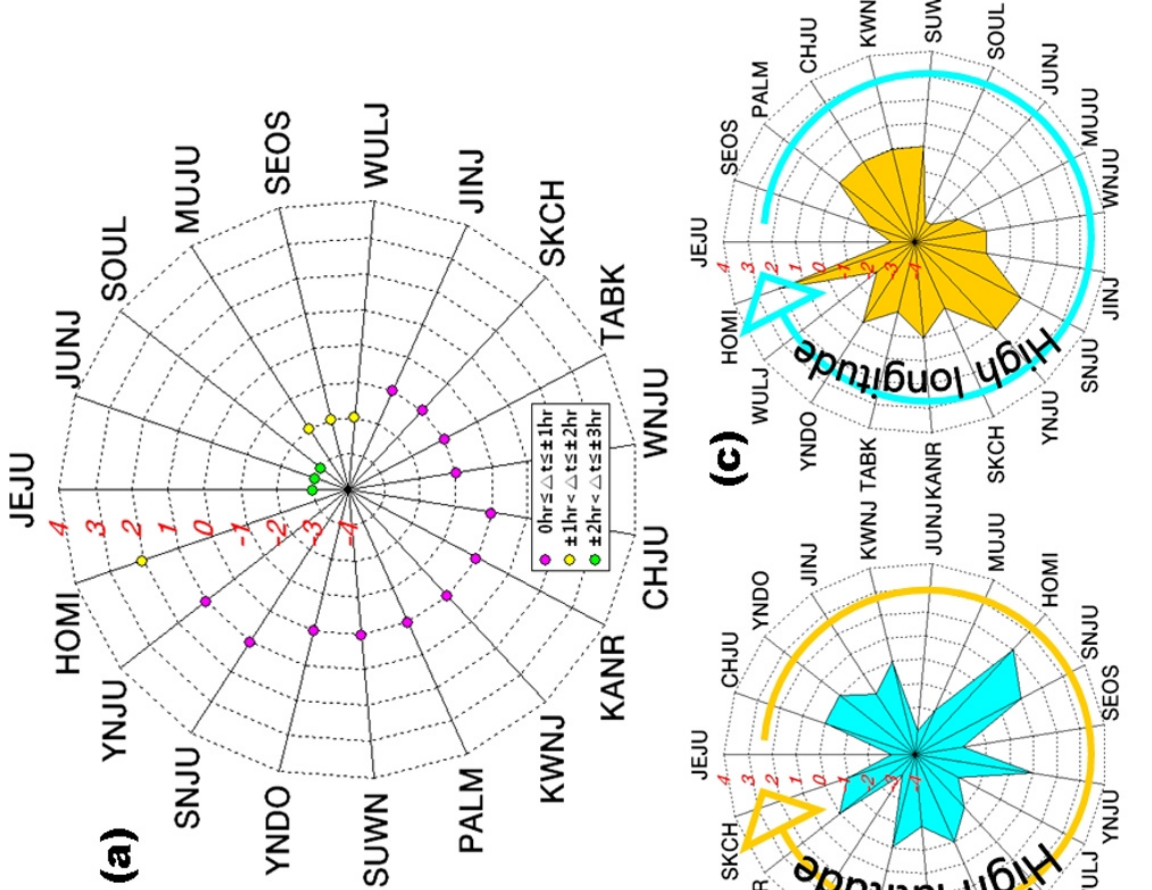

品

$\times 8$

造

월

등

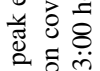

웛

छ

응

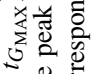

崩

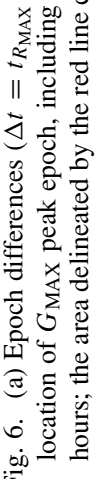


data may have been biased, as mentioned above. We are aware of some considerable problems with using radiosondes during the progress of a typhoon; for example, even though the distance between the GPS and radiosonde sites was relatively short, significant biases in PWV between two sensors at HOMI station were detected, due mainly to the uncertainty in radiosonde measurements and caused primarily by the departure from the zenith ascent direction as a result of strong winds.

Radiosondes are designed to measure atmospheric profiles along the zenith direction while they drift with varying wind conditions (Leick, 1995). Therefore, the consistency in PWV estimations by the two observing systems, GPS and balloon-based radiosonde, depends on the degree of atmospheric inhomogeneity (Liou et al., 2001). Song et al. (2008) demonstrated that the larger RMSE and bias between GPS and radiosonde measurements during severe weather is due to the inconsistencies in the balloon-based radiosonde measurements deflected from the vertical by strong winds. Consequently, it can be concluded that the estimation of water vapor from a radiosonde may not be reliable during severe weather events. Thus, when permanently tracking GPS networks are available, estimates of water vapor based on GPS signals should be incorporated.

Figure 5(a) and (b) shows the 1-h maximum rainfall $\left(R_{\mathrm{MAX}}\right)$ and the maximum GPS PWV $\left(G_{\mathrm{MAX}}\right)$ in increasing latitudinal order; Fig. 5(c) and (d) shows a scatter plot of $G_{\mathrm{MAX}}$ and $R_{\mathrm{MAX}}$ during the period of no direct impact of typhoon EWINIAR (10:00 hours on July 0709:00 hours on July 08), including the period before the Jangma $^{1}$ (23:00 hours on July 10-12:00 hours on July 11) and the period of direct impact by EWINIAR (10:00 hours on July 08-22:00 hours on July 10), respectively. For comparison, the recorded rainfall data from the AWS operated by KMA were used. The highest value of $G_{\text {MAX }}(76.9 \mathrm{~mm})$ during the typhoon occurred at JINJ station, where the maximum precipitation per hour $(43.5 \mathrm{~mm})$ was recorded by AWS as being in the vicinity of JINJ (about $1.3 \mathrm{~km}$ from the station). Overall, all of the factors considered were relatively larger during the period directly affected by the typhoon. In particular, a stronger correlation between $G_{\mathrm{MAX}}$ and $R_{\text {MAX }}$ during the typhoon is clearly seen in Fig. 5(d). $G_{\mathrm{MAX}}$ correlated higher with $R_{\mathrm{MAX}}$ (correlation coefficient $\left.r^{2}=0.41\right)$ during typhoon EWINIAR as compared to the quiet weather period (correlation coefficient $r^{2}=0.10$ ). These values show that the PWV derived from the groundbased GPS is closely associated with the rainfall in this severe weather event. For a more detailed analysis, we computed the correlation coefficient between $G_{\mathrm{MAX}}$ and $R_{\mathrm{MAX}}$ using the information from the stations located within a 30-km radius of EWINIAR's track (JEJU, CHJU, MKPO, KWNJ, SEOS, SUWN and WNJU). The correlation coefficient $\left(r^{2}\right)$ derived from the stations that are relatively close to the typhoon's path reached 0.76 , which is higher, as compared to the correlation coefficient based on all sites. Although this strong correlation is still insufficient as a standalone index for heavy rainfall prediction, continuous moni-

\footnotetext{
${ }^{1}$ Jangma is the seasonal monsoon with heavy rainfall in the Korean peninsula.
}

toring of GPS PWV variation is a credible source of water vapor information to support numerical weather forecasting for short-term rainfall prediction. More extended study is needed to properly quantify the relationship between the GPS PWV and the actual precipitation.

We then compared the peak time of $G_{\mathrm{MAX}}$ with the $R_{\mathrm{MAX}}$ during the passage of typhoon EWINIAR. Figure 6(a) illustrates the epoch difference between the peak epoch of $G_{\mathrm{MAX}}$ and the corresponding peak epoch of $R_{\mathrm{MAX}}$ for the period of direct impact, and Fig. 6(b) and (c) demonstrates the time lag for the same period in latitude and longitude, respectively. The geographical location of $G_{\text {MAX }}$ peak time, as a function of the typhoon's progress, is shown in Fig. 6(d). In general, the epochs of $R_{\mathrm{MAX}}$ occur near the epochs of $G_{\text {MAX }}$. Note that the recorded $R_{\text {MAX }}$ preceded $G_{\text {MAX }}$ for half of the stations $(\sim 55 \%)$. Also, as seen in Fig. 6(a), the epoch of $G_{\text {MAX }}$ is completely in accord with that of $R_{\text {MAX }}$ at six stations. The differences of both peak epochs fall well within \pm 3 -h range, except for three sites: CNJU, MKPO, and TEGN. It is difficult to explain at this point why the differences are not consistent at all stations. It is obvious that there is no specific relationship between the epoch differences and the geographical positions (see Fig. 6(b) and (c)). However, it is clear from Fig. 6(d) that the variation in $G_{\text {MAX }}$ peak epoch followed the northeast direction, similarly to the route of typhoon EWINIAR. This result indicates that GPS PWV estimates closely follow the typhoon's track. Therefore, the spatio-temporal monitoring of PWV based on dense GPS networks can provide a new data source to forecast and assess the impact of typhoons. The overall results suggest that GPS PWV, if evaluated in near-real time, represents a consistent means for sensing and tracking the actual severe weather events.

\section{Concluding Remarks}

In this paper, the GPS PWV was estimated from permanent GPS stations in South Korea with the aim of assessing the performance of GPS meteorology during a severe weather event. The time series of PWV derived from GPS clearly increased before and during the passage of typhoon EWINIAR and then decreased rapidly immediately after the typhoon had passed, later recovering to its nominal values.

Data from an MTSAT water vapor image, a radar image, and a PWV contour map recorded during the passage of typhoon EWINIAR were also compared. From the comparison with satellite/radar images, we confirmed that the horizontal distribution of the GPS PWV has a strong correlation to the spatio-temporal change of water vapor. In addition, the Korean weighted mean temperature equation, as an alternative to Bevis's formula, was used to obtain an improvement in the accuracy of the GPS PWV estimation. We demonstrated that the locally appropriate WMTE model, which is used to convert ZWD to the PWV, can reduce the relative biases of PWV estimated from GPS signal delays.

The data recorded from GPS PWV and radiosonde PWV showed an agreement at the 2.5-mm (RMSE) level after the bias between the two sensors was removed. This result is more accurate than that reported in another study where the locally weighted mean temperature model was not used to monitor a severe weather event (Song et al., 2008). We 
also showed that the PWV estimated by the GPS meteorology technique is closely related to the maximum of rainfall and the peak epoch of maximum hourly rainfall during the progress of typhoon EWINIAR.

The results of this study further confirm that GPS meteorology may be efficiently used to sense water vapor and, consequently, to clarify the complex characteristics of water vapor distribution and its temporal change during severe weather events. Also, the high-density Korean GPS Network (KGN), with over 90 stations (introduced by Song and Yun, 2008) and an average spacing of $\sim 30 \mathrm{~km}$, used in this study provides a useful tool for operational weather forecasting (Faccani et al., 2005), provided that the data can be processed in near-real time. To further understand the process of variation in precipitable water estimated from ground-based GPS stations and its role in the determination of heavy precipitation caused by typhoon EWINIAR (and similar weather events), an additional study, involving a numerical weather model, is necessary.

Acknowledgments. This work was supported by the Korea Research Foundation Grant funded by the Korean Government (KRF-2008-357-D00272). We would like to acknowledge the reviewers and the editor-in-chief for their extraordinarily prompt reviews and very insightful comments on this manuscript.

\section{References}

Bevis, M., S. Businger, T. A. Herring, C. Rocken, R. A. Anthes, and R. H. Ware, GPS meteorology: Remote sensing of atmospheric water vapor using the Global Positioning System, J. Geophys. Res., 97, 1578715801, 1992.

Davis, J. L., T. A. Herring, I. I. Shapiro, A. E. Rogers, and G. Elgered, Geodesy by radio interferometry: Effects of atmospheric modeling errors on estimates of baseline length, Radio Sci., 20, 1593-1607, 1985.

Duan, J., M. Bevis, P. Fang, Y. Bock, S. Chiswell, S. Businger, C. Rocken, F. Solheim, T. V. Hove, R. Ware, S. McClusky, T. A. Herring, and R. W. King, GPS meteorology: Direct estimation of the absolute value of precipitable water, J. Appl. Meteorol., 35, 830-838, 1996.

Elgered, G., J. M. Johansson, and B. O. Ronnang, Measuring regional atmospheric water vapor using the Swedish permanent GPS network, Geophys. Res. Lett., 24, 2663-2666, 1997.

Faccani, C., R. Ferretti, R. Pacione, T. Paolucci, F. Vespe, and L. Cucurull, Impact of a high density GPS network on the operational forecast, $A d v$. Geosci., 2, 73-79, 2005.

Foster, J., M. Bevis, S. Businger, and Y.-L. Chen, The Ka'u storm: Imaging precipitation water using GPS, J. Geophys. Res., 108(D18), 4585, doi:10.1029/2003JD003413, 2003.
Frank, W. M., The structure and energetics of the tropical cyclone-I. Storm structure, Month. Weath. Rev., 105(9), 1119-1135, 1977.

Hong, C. K., D. A. Grejner-Brzezinska, and J. H. Kwon, Efficient GPS receiver DCB estimation for ionosphere modeling using satellite-receiver geometry changes, Earth Planets Space, 60(11), e25-e28, 2008.

Jade, S., M. S. M. Vijayan, V. K. Gaur, T. P. Prabhu, and S. C. Sahu, Estimates of precipitable water vapour from GPS data over the Indian subcontinent, J. Atmos. Sol.-Terr. Phys., 67, 623-635, 2005.

Leick, A., GPS satellite Surveying, 560 pp., John Wiley and Sons, 1995.

Lichten, S. M. and J. S. Border, Strategies for high precision GPS orbit determination, J. Geophys. Res., 92, 12751-12762, 1987.

Liou, Y.-A. and C.-Y. Huang, GPS observation of PW during the passage of a typhoon, Earth Planets Space, 52, 709-712, 2000.

Liou, Y.-A., Y.-T. Teng, T. Van Hove, and J. Liljegren, Comparison of precipitable water observations in the near Ttopics by GPS, microwave radiometer, and radiosondes, J. Appl. Meteorol., 40, 105-115, 2001.

Mendes, V. B., Modeling the neutral-atmosphere propagation delay in radiometric space techniques, Ph.D. dissertation, Department of Geodesy and Geomatics Engineering Technical Report No. 1999, University of New Brunswick, New Brunswick, Canada, 1999.

Rocken, C., T. V. Hove, J. Johnson, F. Solheim, R. Ware, M. Bevis, S. Chiswell, and S. Businger, GPS/Storm-GPS sensing of atmosphere water vapor for meteorology, J. Atmos. Ocean. Technol., 12, 468-478, 1995.

Ross, R. J. and S. Rosenfeld, Estimating mean weighted temperature of the atmosphere for Global Positioning System applications, J. Geophys. Res., 102(D18), 21,719-21,730, 1997.

Schüler, T., On ground-based GPS tropospheric delay estimation, Doctor's Thesis, Studiengang Geodsie und Geoinformation, Universitt der Buundeswehr Munchen, Germany, Vol. 73, Neubiberg, 2001.

Solbrig, P., Untersuchungen ber die Nutzung numerischer Wettermodelle zur Wasserdampfbestimmuna mit Hilfe des Global Positioning Systems, Diploma Thesis, Institute of Geodesy and Navigation, University of FAF Munich, Germany, 2000.

Song, D. S., Accuracy improvement of precipitable water vapor estimation by precise GPS analysis, Ph.D. Dissertation, SungKyunKwan University, South Korea, 2006 (in Korean).

Song, D. S. and H. S. Yun, Crustal strain pattern analysis of Korean Peninsula using repeated GPS measurements, KSCE J. Civil Engineering, 12(4), 267-273, doi:10.1007/s12205-008-0267-x, 2008.

Song, D. S., H. S. Yun, and D. H. Lee, Verification of accuracy of precipitable water vapour from GPS during typhoon RUSA, Surv. Rev., 40, 307, 19-28, 2008.

Wang, J., L. Zhang, and A. Dai, Global estimates of water-vapor-weighted mean temperature of the atmosphere for GPS applications, J. Geophys. Res., 110, D21101, doi:10.1029/20005JD006215, 2005.

Yan, X., V. Ducrocq, P. Poli, G. Jaubert, and A. Walpersdorf, Mesoscale GPS Zenith Delay assimilation during a Mediterranean heavy precipitation event, Adv. Geosci., 17, 71-77, 2008.

D.-S. Song (e-mail: song.306@osu.edu) and D. A. Grejner-Brzezinska 